\title{
Discovering Argumentative Patterns in Energy Polylogues: A Macroscope for Argument Mining
}

\author{
Elena Musi ${ }^{1} \cdot$ Mark Aakhus $^{2}$
}

Published online: 3 January 2018

(C) The Author(s) 2018. This article is an open access publication

\begin{abstract}
A macroscope is proposed and tested here for the discovery of the unique argumentative footprint that characterizes how a collective (e.g., group, online community) manages differences and pursues disagreement through argument in a polylogue. The macroscope addresses broader analytic problems posed by various conceptualizations of large-scale argument, such as fields, spheres, communities, and institutions. The design incorporates a two-tier methodology for detecting argument patterns of the arguments performed in arguing by an interactive collective that produces views, or topographies, of the ways that issues are generated in the making and defending of standpoints. The design premises for the macroscope build on insights about argument patterns from pragma-dialectical theory by incorporating research and theory on disagreement management and the Argumentum Model of Topics. The design reconceptualizes prototypical and stereotypical argument patterns for characterizing large-scale argumentation. A prototype of the macroscope is tested on data drawn from six threads about oil-drilling and fracking from the subreddit Changemyview. The implementation suggests the efficacy of the macroscope's design and potential for identifying what communities make controversial and how the disagreement space in a polylogue is managed through stereotypical argument patterns in terms of claims/premises, inferential relations, and presentational devices.
\end{abstract}

Elena Musi

em3202@columbia.edu

Mark Aakhus

aakhus@rutgers.edu

1 Data Science Institute, Columbia University, 476 Riverside Drive, New York, NY 10115, USA

2 School of Communication and Information, Rutgers University, 4 Huntington Street, New Brunswick, NJ 08901, USA 
Keywords Argument mining $\cdot$ Discourse analysis $\cdot$ Change my view $\cdot$ Reddit $\cdot$ Text analytics $\cdot$ Computational methods

\section{Introduction}

It has long been recognized that argumentation is a property of human groups, organizations, and communities. Key to this recognition are the particular and characteristic means collectives develop for managing differences and pursuing disagreements in polylogues (i.e., discussions, deliberations, and controversies involving multiple players, pursuing many positions across many places). ${ }^{1}$ Yet, it remains a fundamental empirical and methodological challenge to investigate and discover the unique argumentative footprint (e.g., arguing processes, argument products, and argumentation procedures) ${ }^{2}$ that characterizes how particular collectives manage differences and pursue disagreement. Argumentation theories have offered rich ideas for understanding the nature and quality of argumentation at a large-scale, such as fields (Toulmin 1958; Willard 1981), spheres (Goodnight 2012; Rowland 1986; Zarefsky 2014), communities (McKerrow 1980), and institutions (Van Eemeren 2010). Despite the important conceptualizations within each theory about key distinguishing features (e.g., field dependent and independent criteria), the scale at which groups, organizations, communities, and societies behave is often either too big, slow, fast, or complex. This remains a profound challenge for adequately realizing the empirical potential of these rich conceptualizations for describing and evaluating the argumentative footprint of collectives and their polylogues.

Indeed, fields, spheres, communities, and institutions are still often used to investigate argumentation in terms of the trees and not the forests for which they could be used. Recent attention to the potential of computational tools to be designed as macroscopes for examining argumentation at a large scale, however, suggests a promising direction for argumentation research (Jackson and Lambert 2015). Börner (2011) defines macroscopes as devices for making sense of the "infinitely complex" in the way telescopes make the immensity of space and microscopes make the incredibly small visible and available for comprehension. A macroscopic view provides 'a 'vision of the whole,' helping us 'synthesize' the related elements and detect patterns, trends, and outliers while granting access to myriad details" (Börner 2011: 60). The proliferation of big data via new media that is relevant to argumentation offers an important opportunity for argumentation researchers to engage in building macroscopes for inquiry into argumentation at a large scale.

Early efforts at building macroscopes for argumentation analysis are highly suggestive about the possibilities of designing tools for inquiry into the argumentation of human collectives and their polylogues while emphasizing the fundamental importance of adapting computational techniques to argumentation phenomena. Jackson and Lambert (2015), for instance, devised a macroscope to investigate

\footnotetext{
1 See Lewiński and Aakhus (2014) and Aakhus and Lewiński (2017) for discussion of polylogue.

2 See Wenzel (1979) for explanation of three senses of argument.
} 
argument in public health controversies about vaccinations uncovering lexical patterns. Aakhus et al. (2016) built a macroscope with a methodology for mapping the argumentative roles played by organizations that integrated social network analysis of URL linking behavior of organizations related to the controversy over fracking with natural language processing techniques to detect patterns of language use in the about-pages of the organizations in the network. Yet, despite these preliminary attempts, there are currently no technologies in Argument Mining for the combined detection of argument structures and argumentative reasoning (i.e., argument products) as deployed in making and defending positions on issues particular to the collective (i.e., argument process). Herein lies a significant challenge for a computational social science of argumentation (i.e., Argument Mining).

There are two key empirical challenges to be addressed in designing a macroscope for argument mining of argument structures and argumentative reasoning characteristic of the ways a particular collective manages disagreement: (1) detecting these features of argument in social media content (e.g., discussion fora) and (2) distinguishing argument used in disagreement management from argument used for other purposes. As will be discussed in Sect. 2, the pragmadialectical conceptualization of argument patterns offers an important starting point for designing a macroscope for the argument mining of argument structures and argumentative reasoning characteristic of a collective and its polylogues. The development of the macroscope, however, draws further inspiration from disagreement management approach (e.g., Jackson and Jacobs 2006) and Argumentum Model of Topics (e.g., Rigotti and Morasso 2010) to pursue its empirical aims in reconstructing the argumentative footprint that characterizes how particular collectives manage differences and pursue disagreement in polylogues. These aims ultimately have significant potential complementarities with the pragma-dialectical approach. On this basis, a two-tiered method of annotation is proposed in Sect. 3 for the detection of prototypical and stereotypical argumentative patterns as the basic design elements for an argument mining macroscope for argument patterns. Sections 4 and 5 report the efficacy of the design as tested on a use case drawn from discussion threads about oil drilling and fracking from the subreddit Changemyview. The achievements, limitations, and directions for future work are discussed in the final section.

The main contributions of the design and implementation of a prototype macroscope for stereotypical argument patterns include: first, the refinement and extension of the concept of prototypical and stereotypical argument patterns; second, the specification of a systematic and scalable procedure for reconstructing both prototypical and stereotypical argumentative patterns as used by collectives in polylogues; third, the detection of argumentative features indicating how discourses are built around argumentative patterns among different groups of arguers, which in this case deal with fracking and oil drilling issues. Moreover, this endeavor constitutes a next step for realizing the potential of extant Argumentation Theory by enabling argument analysis to realize the description and evaluation of large-scale argumentation and for Computational Social Science by providing insights on the 
changes brought about by user-generated comments in community building, stance negotiation and social influence.

\section{Design Theoretical Requirements: Argument Patterns}

Central to conceptualizations that consider argumentation at large scales, such as communities, institutions, fields, and spheres, lies the basic insight that the means of managing disagreement - arguing (process), arguments (products), and argumentation (procedures) - emerge or are invented and sustained by the collective (e.g., Goodwin and Wenzel 1979; Wenzel 1979). These means are consequential for the discourse about some domain and thus knowledge and action (e.g., Goodnight 2012; Jacobs and Jackson 2006; Willard 1996; Zarefsky 2014). For instance, Toulmin's concept of "field of argument" (1958) highlights that while all communities depend on field independent criteria for evaluating arguments, communities become specialized by developing field dependent criteria for evaluating argument about particular domains of knowledge and action. Zarefsky (2014) has investigated different criteria to define and investigate argument fields, namely subject-matter, form, purpose and audience. Goodnight (2012) contrasts fields, which are technical, specialized spheres of argument, with the public and private spheres by illustrating how the practices for grounding argument in these different spheres change how uncertainty is resolved and created. Each focuses on the constraints collectives impose, formally and informally, on the means for managing differences and pursuing disagreements with a concern for the nature and quality of arguments and arguing. The crucial shift for understanding large scale argument is attending to the arguments and arguing characteristic of the collective not just the individual moves in arguing or arguments made.

The extended pragma-dialectical theory (e.g., Van Eemeren 2010, 2017) has addressed large scale argumentation with its attention to institutional argumentation and in developing the concept of argument patterns. The concept aims to "pave the way for a more thorough account of the relationship between context-independency and context-dependency in argumentative discourse" initially envisioned by Toulmin for understanding differences among specialized fields in terms of argumentation (Van Eemeren 2016). In Pragma-Dialectics, the dichotomy between field-invariant and field-dependent factors is at the core of strategic maneuvering, which "refers to the continual efforts made in all moves that are carried out in argumentative discourse to keep the balance between reasonableness and effectiveness" (Van Eemeren 2010: 39). The underlying assumption is that communicative activity types associated with particular institutional contexts constrain the topical potential, audience demand, and appropriate presentational devices participants can use to realize the institutional point of interaction and address the critical questions at stake in the institutional discourse (Van Eemeren 2010; Van Eemeren and Houtlosser 2015). Participants make strategic maneuvers in addressing critical questions with their communicative moves that realize topical potential, adjust to audience demand, and exploit appropriate presentational devices (Van Eemeren 2010: 94-96). 
The relationship between strategic maneuvering and the macro-context of activity types has as discursive counterparts argumentative patterns, which are constellations of "argumentative moves in which a particular kind of argumentation structure or a particular combination of argument schemes is exploited in defense of a particular type of standpoint" (van Eemeren and Garssen 2013: 7). Argument patterns are combinations of argument structures, inferential patterns, and presentational devices that work in making and defending standpoints within particular institutionalized communicative activities and thus are responsive to the types of critical questions specific to the arguments made in an activity type (Van Eemeren 2016). Pragma-dialecticians conceptualized argument patterns for the analysis of strategic maneuvering in institutional contexts (i.e., the uses of argument products within arguing process).

The pragma-dialectical analysis of argumentative patterns has so far been interested in prototypical argument patterns, which are argumentative moves that are "pre-eminently instrumental in reaching the desired kind of outcome," - that is, the institutional point of a communicative activity found in contexts featuring conventionalized institutional preconditions such as law, legislation, and medicine (Van Eemeren 2016). Pragma-dialecticians have qualitatively investigated the prototypical argument pattern containing pragmatic argumentation in the legislative (Andone 2016; Van Eemeren and Garssen 2014; Garssen 2016), legal (Feteris 2016), medical (Henkemans 2016) and scientific (Wagemans 2016) domains.

To identify prototypical argument patterns, pragma-dialectical researchers first theoretically define the constraints, or primary institutional preconditions, conventionally imposed by the institutional context of interest on communicative activity. These preconditions are defined as primary in that these are "as a rule official, usually formal, and often procedural" (Van Eemeren 2016). For example, the material starting points of the discussion characteristic of parliamentary debates, the type of standpoints in medical advertisements, and the procedural starting points in the scientific domain, that set a finite range of possible reasoning. The analysts then show through empirical analysis of text how the prototypical argumentative pattern under consideration is adapted to the particular institutional context. In European plenary parliamentary debates about legislative issues, for instance, the flows of subsequent arguments seem to be largely dependent on the issues advanced by the rapporteur of the parliamentary committee report, raising mostly pragmatic and/or complex problem solving argumentation (Garssen 2016). In the medical domain, over-the-counter medicine advertisement needs to comply with institutional guidelines aimed at guaranteeing the consumers' safety as well as to make the strongest possible case in promoting pharmaceutical drugs through advertising. As a result, the prototypical argumentative patterns envisage a standpoint of the prescriptive type supported by a pragmatic argument (Henkemans 2016).

As pointed out by Van Eemeren (2016, 2017), this extant research has involved qualitative investigations of small samples of exemplary data focused on patterns containing pragmatic argumentation across a range of institutional contexts. Pragma-dialecticians have also defined stereotypical argumentative patterns as the prototypical patterns that are more frequent for a particular communicative activity type (Van Eemeren 2016). However, this remains for future work as no extant 
research has established which prototypical patterns would qualify as stereotypical argument patterns based on their frequency of use (see Van Eemeren 2017, p. 179).

A macroscope could be built modeled on the pragma-dialectical approach studying one prototypical argument pattern as it is realized across a range of institutional settings. This would of great interest since it would further understanding of whether a pattern has proliferated and for assessing whether argumentative behavior depends on particular contexts (Van Eemeren 2017). The aim in the present study, however, differs from the pragma-dialectical approach. The current study seeks to design a macroscope for investigating and discovering the unique argumentative footprint that characterizes how particular collectives manage differences and pursue disagreement. Such a goal emphasizes characterizing and analyzing the collective argumentative behavior in a polylogue for what it achieves argumentatively (or not). This differs from examining one prototypical pattern across a range of contexts. In this way, it is possible to assess the behavior and communicative norms of a collective which is also a crucial turn in understanding large scale argumentation (Aakhus and Lewiński 2011, 177-179; see also Aakhus et al. 2013). The pragma-dialectical approach to prototypical and stereotypical argument patterns presents some key issues for pursuing the goals of the current study. First, the pragma-dialectical conceptualization of prototypical patterns depends on an a priori designation of institutions and communicative activity types that may not be readily predetermined in, for instance, social media discourses. Second, as foreshadowed in Extended Pragma Dialectical theory, secondary institutional conditions are important to consider in characterizing the argumentative realities of groups, communities, organizations, and other collectives and movements. These conditions are informal and more substantive than primary conditions (Van Eemeren 2016; Van Eemeren and Garssen 2010). Third, the discovery of stereotypical patterns is not simply a question of frequency but of distinguishing which argumentative patterns are used in managing disagreement relative to a collective's evolving expectations about critical questions and how to address them may be especially dependent on informal and substantive conditions. Fourth, normative theories work from given argument forms and features in discourse but new or reinvented forms and features of discourse are not pre-given and must be discovered. In regard to argument mining, it is important to capture the natural ways participants call-out and make disagreeable what others have communicated to recover the community based norms for arguments and arguing (Aakhus et al. 2013).

The macroscope proposed here seeks to attend to the informal, implicit, emergent and substantive aspects of how collectives argue. This calls for attention to the dynamics of disagreement space to identify when and how disagreement is managed (Aakhus 2013). One of the key insights of the disagreement management perspective is that the propositional content that gets developed in interaction depends on the way parties respond to each other. It is possible that propositional content can be used in ways that are substantively relevant and pragmatically irrelevant to resolving the disagreement and vice versa (e.g., Jacobs and Jackson 1992). Thus it is important to distinguish not just when argument patterns are plausibly present in discourse but when argument patterns are used, or function, in 
the management of disagreement and what argument patterns emerge through interaction. These are largely matters of discovery that are only partially amenable to a priori analysis. The informal, often implicit argumentative norms of a collective (i.e., secondary institutional conditions) are realized in argument forms and arguing processes that, from a disagreement management perspective, may take nonstandard, non-prescriptive forms and yet serve argumentative functions (Jacobs and Jackson 2006). Many online fora, moreover, lack or have minimal primary institutional preconditions that rarely, if ever, restrict or impose argument schemes. To investigate what controversial aspects are associated to what reasoning types, the Argument Model of Topics framework is implemented (see Sect. 3). The AMT singles out material, contextual premises from abstract procedural ones, thus enabling hypothesis about secondary institutional conditions in play for a community.

To more adequately reconstruct the argument patterns of groups and communities engaging in online debates via argument mining, it is, therefore, necessary to unravel stereotypical argumentative patterns in a manner that departs from the pragma-dialectical approach. For the proposed macroscope, three key guiding assumptions are made. First, arguments patterns include presentational devices, inferential patterns, and argument structures as deployed in making and defending standpoints for which doubt or disagreement has been raised by other participants. Second, prototypical argumentative patterns are conceived in this study, according to terms borrowed from cognitive science (Rosch and Mervis 1975), as complex argumentative moves that are perceived by members as more central, than other theoretically possible moves in a context. Third, argumentative patterns are interactively negotiated in the discussion (O'Keefe 1992) and thus the centrality of patterns used can be hypothesized by the analyst only by looking at their frequency of use relative to the nature of the discussion. Thus, for a macroscope that mines for argumentative patterns in the polylogues of collectives, such as in their social media content, the concepts of prototypical and stereotypical argument patterns are redefined here to address the discovery of a collective's argumentative footprint. Adopting a primarily discursive perspective, prototypical argument patterns are those that happen to be more frequently employed by the different participants in a discussion. Stereotypical argumentative patterns refer to those prototypical patterns that become targets of (dis)agreement in an ongoing polylogue since their standpoints, their arguments, and general line of reasoning typically challenged or shared by different parties. This approach aims to describe the argumentative reality of a collective-its unique footprint of argument patterns that in turn shape the lines of the discussion that diffuse through a polylogue.

\section{Design Elements of a Macroscope for Stereotypical Argument Patterns}

Macroscopes, as envisioned by Börner (2011), can range from cyberinfrastructures to web services to standalone devices that offer plug and play hardware and software that are easy to extend, share, and customize. A macroscope extends data 
analytics into computational social science as strategies are required that justifiably integrate tools and techniques into a suitable methodology for the inquiry at hand. Underlying a macroscopic turn is a conviction that observational and analytic tools are part and parcel of perceiving, inferring, and reasoning about phenomena, and thus the design of procedures that integrate tools and techniques is essential. For a multidimensional phenomenon like argumentation that involves interpretation, there is considerable room for inventions and innovations that enable a vision of the whole while grasping key details. Given the developments on information retrieval, text analytics, natural language processing, social network analysis, and the like, it is possible for argumentation researchers to assemble macroscopes from readily available services and software (see Aakhus et al. 2016; Jackson and Lambert 2015) as well as to engage in invention of whole new instruments. The macroscope must deliver a credible view, thus the design of the procedures that enable the mascroscope are crucial and constitutes a key focus here.

In view of the state of the art regarding argument patterns, the aim here is to design a scalable procedure for a macroscope that identifies stereotypical argumentative patterns. The procedure supports the generation of outputs that scaffold views, or topographies, of the argumentative realities of collectives to shed light on the argumentative norms and practices particular to different collectives, deliberations, or controversies. The search for stereotypical argumentative patterns, being probabilistic in nature, calls for corpus-based observation of the multidimensional features indicative of argument patterns: presentational, structural, and inferential aspects. The procedure supports the mapping of how these features are integrated by individuals encountering differences or disagreements. Once the uses of patterns in the context of differences and disagreement are detected, these can be aggregated to determine stereotypical argument patterns. The proposed design incorporates a multi-level annotation scheme that is applied via a two-tiered approach, described in the next section, that generates a topography of stereotypical argumentative patterns.

\subsection{Tier 1: Annotating Procedures for Identifying Prototypical Argumentative Patterns}

The key features relevant to detecting argument patterns include structural (premises, claims), inferential (argument scheme), and presentational (heteroglossic resources) features. The procedures related to each of these features described here were implemented by an expert annotator in order to establish the preliminary viability of the procedure for the purpose of detecting argument patterns.

For the annotation of the argument structure the distinctions proposed by Peldszus and Stede $(2013,2016)$ have been adopted. The proposition is taken as a basic unit of observation where a claim is a proposition that expresses an assertive speech act towards which the user is committed at the moment of utterance and linked premises are propositions which bear supportive force only if considered conjoined (Freeman 2000, 2011). We do not make any distinction between claims and major claims, since the latter generally coincide in Change My View (described in Sect. 4) with the title of the post. The annotation is illustrated in example 1: 
(1)

CMV: [Bernie Sanders' energy policy is based in fantasy $]_{\text {Claim. }}$.

[He has expressed a desire to ban fracking, phase out nuclear, and obviously hates coal] $]_{\text {linked_premise. [Those methods accounted for } * * 85 \% \text { of all our }}$

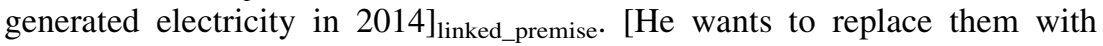
wind, solar, geothermal, and biomass] $]_{\text {linked_premise. [Those methods accounted }}$

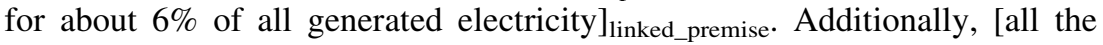
methods that Sanders favors are very geographically dependent and require grid-scale energy storage for which we have no viable solutions $]_{\text {Claim. }}$.

The inferential relations connecting premises to claims or claims to major claims are annotated according to the guidelines proposed by Musi et al. (2016), which have been empirically verified in terms of inter-annotator agreement. The guidelines are based on a simplified version of the Argumentum Model of Topics' (AMT) taxonomy of argumentation schemes summarized in Fig. 1 (Rigotti and Morasso 2009). Compared to other contemporary approaches (i.e., Perelman and Olbrechts-Tyteca 1969; Kienpointner 1992; Walton et al. 2008), the AMT has proven to be suitable for annotation purposes since it avoids a proliferation of argumentation schemes, it is hierarchical and based on mutually exclusive semantic principles (Musi 2016a; Musi et al. 2016). Drawing from Cicero (Topica, 8) argument schemes are distinguished into three main classes:

- Intrinsic argument schemes the state of affairs expressed by the premises and the state of affairs expressed by claims are linked by an ontological relation. ${ }^{3}$

- Extrinsic argument schemes the state of affairs expressed by the premise and the state of affairs expressed by the conclusion are linked by semantic relations but they do not show any ontological relation.

- Complex argument schemes the relation between the premise and the conclusion is not semantic or ontologic, but pragmatic.

Argument schemes from oppositions are, for example, instances of extrinsic argument schemes since the realization of the state of affairs expressed in the premise entails that the state of affairs expressed in the claim is unrealized (e.g., "The suspect was in Paris on Friday 29th. He was not for sure on the scene of the crime in London"). On the other hand, causal argument schemes from the effect to the cause constitute a typical case of intrinsic argument scheme since they state the presence of a connection between the existence of the state of affairs expressed in the premise and that expressed in the claim.

Moreover, in the AMT argument schemes are conceptualized as inferential relations combining procedural and material premises (Rigotti and Morasso 2010). The latter are premises of contextual nature that include the endoxon (i.e., common ground knowledge about the context) and the datum (i.e., new information provided in the dialogue). Material premises allow the procedural premises, which are abstract, to become relevant to the specific situation, showing that argument schemes are not simply abstract rules of reasoning, but are tied to the contextual

\footnotetext{
${ }^{3}$ For a comprehensive definition of every different type of argument schemes see Rocci (2017).
} 


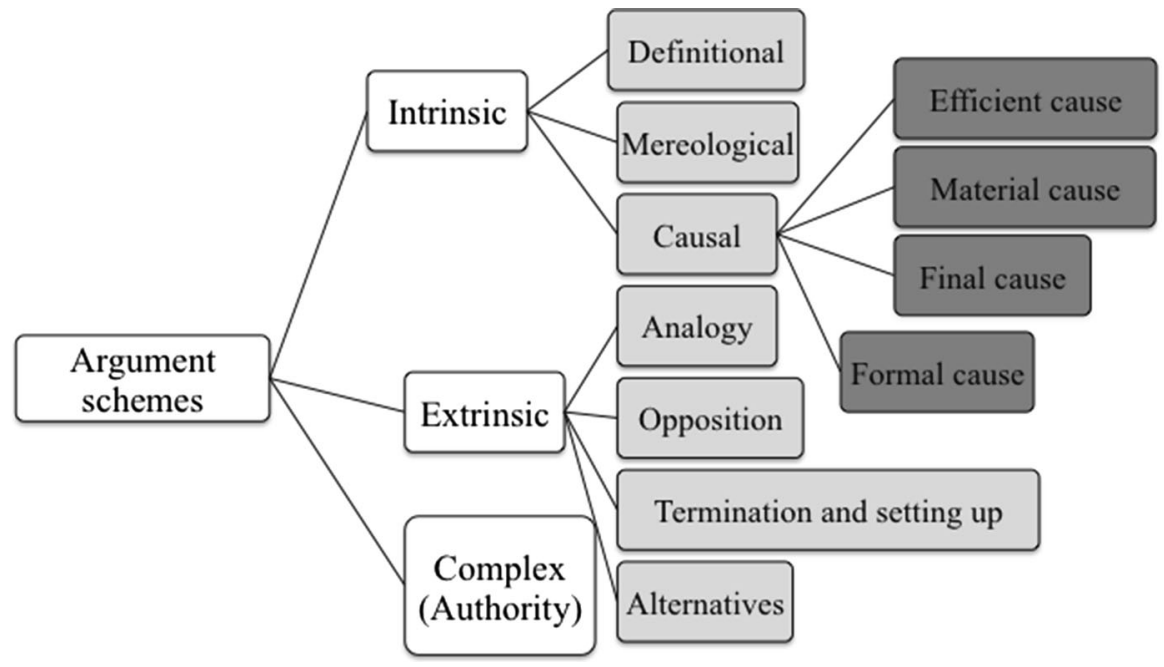

Fig. 1 The AMT taxonomy of argument schemes in a nutshell

specimena. The reconstruction of a simple instance of argumentation such as "We cannot make brownies. We've run out of chocolate" would be spelled out as in Fig. 2.

At the level of the syntax of the argument, only the proposition functioning as datum and that functioning as claim are expressed. The procedural premises as well as the endoxon are left implicit and need to be reconstructed in order to map the semantics of the argument.

The presentational level has been annotated for modals and evidentials. Presentational devices in Argumentation include a wide variety of linguistic items and constructions, ranging from humor to tropes and other figures of speech (Fahnestock 1999) which might bear a rhetoric function when attested in argumentative discourse. We have focused on modals and evidentials since, when used in m-performative constructions (Nuyts 2001), ${ }^{4}$ they presuppose the presence of argumentation, working as indicators. These two classes of linguistic items are, in fact, used in discourse moves which are central for the management of the disagreement space: modals, indicating that things might be otherwise, are used to point to a possible state of affairs alternative to those initially referred to in the discussion; evidentials, presupposing the presence and the type of sources of information, point to the presence and the type of premises used to back up claims.

At the semantics/argumentative interface, modals and evidentials always work as indicators of argumentative discourse relations by signaling the presence of premises-conclusion relations (Rocci 2008, 2012; Musi 2016a) and by constraining what types of standpoints and premises (Becker et al. 2016; Musi 2016b) and argumentation schemes (Miecznikowski and Musi 2015) that might appear depending on their lexical semantics. These features indicate that that there is a

\footnotetext{
${ }^{4}$ M-performative constructions are deemed as those that express the speaker's current attitude towards a certain state of affairs (Nuyts 2001: 40).
} 


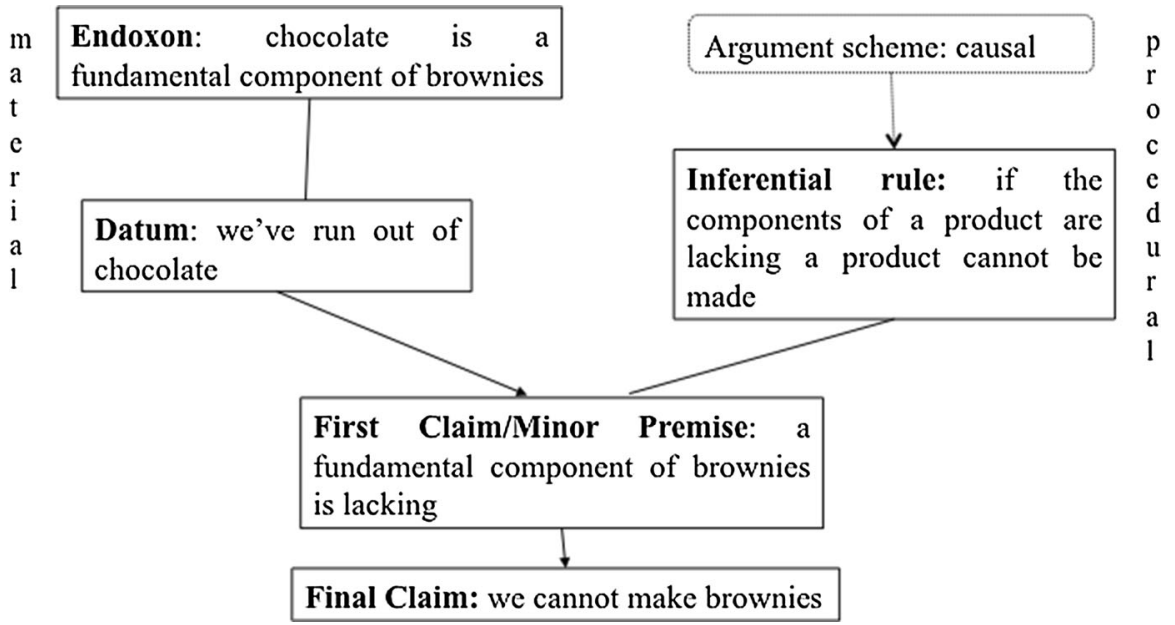

Fig. 2 The inferential configuration of arguments according to the AMT

difference and potential for doubt or disagreement and thus are key to detecting whether a move in a dialogue deploys argument structures and inferential patterns to manage disagreement by expanding or contracting the disagreement space. Moreover, specific sets of modals and evidentials constitute useful clues for finergrained characterization of rhetorical strategies in managing disagreement space. Following Appraisal Theory, modals and evidentials are heteroglossic resources that "present [what is said] as but one proposition among a range of potential alternatives and thereby to open up dialogic space for any such alternatives" (Martin and White 2003: 110; see also White 2000). How modals and evidentials are used to express and negotiate the positions of the participants 'engaging' in multiple voice interactions are annotated to according to White's typology (2003):

- Concurrence: the speaker agrees with the hearer's points of views or shares knowledge with him presenting it as common ground (e.g., obviously, of course);

- Pronouncement: it expresses "intensifications, authorial emphases or explicit authorial interventions or interpolations" (White 2003: 269) (e.g., certainly, definitely, clearly);

- Endorsement: external voices' opinions are construed by the speaker as correct or highly warrantable (e.g., demonstrate, show, indeed);

- Concession: the speaker counters a point of view by first agreeing with some aspects of it (e.g., constructions such as I agree with you/sure, but/however);

- Counter-expectancy: the speaker rejects reasonable viewpoints drawn from expectations (e.g., but, instead) 


\subsection{Tier 2: Annotating Points of Disagreement Management}

The points of disagreement management in the polylogue were identified by labeling appropriate segments of text as Call-Out or Targets. For annotating text as argumentative, Ghosh et al. (2014) envisage two main labels that can apply to text spans-Call-Out/Target—and an anaphoric relation that links the two text spans, as follows:

- Call-Out: is a subsequent action that selects (a part of) a prior action and comments on it in a way that suggests the existence of at least one more or less different points of view;

- Target: is a part of a prior action that has been called out by a subsequent action

- Anaphoric relation: link between a Callout and a Target.

In contrast to the classical definition of argument as "ratio quae rei dubiae facit fidem" (Cicero, Topics 2.8), the notion of Call-out does not make reference to reasonableness and inferences, but appeals to presence of multiple voices possibly bearing different points of view. This polyphony is at the kernel of the concept of controversy loosely defined as "an exchange of opposing views on a problem of mutual interest to the contending parties" (Mills 1968: 1-2). As pointed out by Goodnight (1991) the notion of controversy and its relation to argumentation has been highly debated giving rise to non-overlapping definitions in different fields. In linguistic terms it, thus, constitutes a vague concept. Similarly, the notions of CallOut is characterized by linguistic vagueness (Tuggy 1993): what counts as a different point of view largely depends on the context of discussion. It could, for example, be the case that the truth of an assertion presented as factual by a speaker and, thus, unassailable, happens to be challenged by a hearer that understands it as a standpoint, contrary to the speaker's expectations (Jackson 1992; Van Eemeren et al. 1993).

The assumption here is that the annotation of Call-Out and Targets identifies what is treated, in varying degrees, as controversial by language users. In this way, the Tier 2 coding helps identify the points of disagreement where arguments, as identified in the Tier 1 coding, were used in managing disagreement. The procedure adopts a pragmatic view on argumentation where, "it is the functional context of disagreement management that distinguishes the arguments people make from structurally-related patterns of discourse which serve the functions of illustration, explanation, clarification, and the like" (Jacobs 1987: 230). In addition, the combination of Tier 1 and Tier 2 coding enables an important theoretical and empirical integration of two basic concepts of argument as making-an-argument (Tier 1) and having-an-argument (Tier 2) (O'Keefe 1977; Jacobs and Jackson 1981).

In the present study, the Tier 2 annotations were made by a novice coder because, in contrast to the Tier 1-argumentative components that require encyclopedic knowledge about argumentative features for application (Kiefer 1988), the notions of Call-out, Target and Anaphoric Relationship rely upon speakers' intuitions about arguing. The meaning of the basic codes is lexically transparent as commonsense 
linguistic knowledge as it is likely that any English speaker would agree that a CallOut is the action of challenging and a Target constitutes the entity challenged.

\subsection{Toward a Topography of Stereotypical Argumentative Patterns}

The combination of the Tier 1 and Tier 2 coding provides the base procedure for detecting patterns and variability of arguments in online polylogues both at the individual and at the collective level. The application of Tier 1 and Tier 2 annotations is illustrated in example 2 with a thread from a corpus of discussions about fracking where the Keystone Pipeline is the main topic of discussion:

\section{USER 1}

[...] That being said, [for anyone who says the Keystone Pipeline will limit dependence on foreign oil, your definition of "foreign" is non-white $]_{\text {Target }}$, and you should go fuck yourself. The Keystone Pipeline will reduce the cost of foreign oil - Canada is foreign. And dependence on foreign oil cannot be eliminated. If we got $100 \%$ of our oil from Canada, and Iran shut off the Strait of Hormuz, our oil prices would still go up.

\section{USER 2}

[I would say anything that needs to be shipped by tanker over the ocean would qualify as "foreign". $]_{\text {CallOut1/Target2. Ultimately, the biggest environmental risk }}$ comes from oil spills in the ocean. Over-land spills are generally local in damage and easier to clean. Ocean spills are catastrophic, so if for no other reason, we should try and source as much oil as possible from North America including Mexico.

There are other reasons I'd like to limit business with OPEC, but the focus of this thread is environmental reasons, not economic or moral."

USER 3

[What? Everything that crosses a national border is foreign $]_{\text {CallOut2. }}[\ldots]$

The exchange in Example 2 revolves around the central critical question of arguments from definition: is property $\mathrm{z}$ a definitional trait that allows $\mathrm{x}$ to be categorized as y. User1 overtly attacks the claims of others about the Keystone Pipeline limiting dependence on foreign oil by pointing out that their rationale depends on a biased definition of "foreign" as equivalent of "non white." User1 indicates that Canada provides foreign oil to the U.S. not domestic oil. "Foreign" is being used as a distinction between white/non white countries, which lies outside the definitional properties of what should be considered "foreign." User 2's CallOut performs an undercutter of User1 by defining "foreign" as everything that crosses a natural border, which would qualify Canada as a non foreign country relative to the U.S. User3 overtly rebuts the definition provided by User2 through the queclarative (Sadock 1974) question "What?" that substitutes for an expression of disagreement of the declarative form (i.e., "Your definition of 'foreign' is totally wrong").

There are other arguments used in each comment. User 2, for instance, backs up the claim "we should try and source as much oil as possible from North America including Mexico" through an argument scheme from termination and setting up 
that points to the fact that overland spills are less risky than the ones in the ocean. However, as shown by the annotation of CallOuts and Targets, despite the unfolding of arguments presented by each user, the definition of 'foreign' is the issue which is argumentatively negotiated in a collaborative perspective.

The results of these two annotation layers have, then, been partially merged in this example to illustrate the procedural elements of a macroscope for detecting stereotypical argument patterns and generating a topography of those patterns. To move from prototypical to stereotypical, it is proposed here, it is essential for the claims and the premises identified in the reconstruction of argumentation structure to be included in Targets or Call-Outs in order to capture what arguers treat as relevant uses of argument in disagreement management practices. While the premises and claims brought about by each poster constitute interim argumentative products in the overall discussion, the network of Call-Outs and Targets informs about the argumentative process in the collaborative production of argument products and which products emerge as relevant in shaping the disagreement space among the participants.

\section{Use Case: Stereotypical Argumentative Patterns in Changemyview}

The subreddit discussion forum, Change MyView (CMV) is an exceptional environment for applying and developing the proposed macroscope for detecting argument patterns. Online discussion fora, in general, are places where arguments develop during the interaction among the multiple participants who call-out different aspects of what has been said and thus the lines of difference and disagreement are developed through interaction and participants' argumentative roles are dynamically taken on (see Lewiński 2014). CMV is a version of online discussion that optimizes the exchange of more developed arguments and thus is particularly suitable to elaborate the blueprint discussed above for uncovering of stereotypical argumentative patterns. The key reasons for using text from CMV as corpora for analysis are outlined here along with a description of the corpus built for testing the procedures for identifying stereotypical argument patterns.

\subsection{A Fora for Persuasive Dialogue to Resolve Differences on the Merits of Arguments}

While CMV is an open online forum based on threaded discussion, it has unique rules aimed at fostering a critically rational discussion where differences can be resolved on the merits of the arguments made in discussion. Changemyview is a subreddit "dedicated to the civil discourse of opinions, and is built around one simple idea: in order to resolve our differences, we must first understand them". 5 Participants start a discussion thread by formulating an original post (OP) that expresses an opinion about a topic with a rationale justifying that opinion. Others

\footnotetext{
5 This descriptive definition of the subreddit as well as the following quotations are taken from the CMV wiki (https://www.reddit.com/r/changemyview/wiki/index).
} 
are then invited to take issue with the OP by offering rationales for alternatives that would change the original poster's opinion or rationale. If the original poster is convinced by another participant, then the original poster awards that participant a delta point and explains why the alternative changed the original poster's view.

To facilitate the CMV discussion, participation in the fora is regulated by submission and comment rules, summarized here:

Submission Rules:

1. Try to explain the reasoning behind your view, not just what that view is $(500+$ characters required).

2. You must personally hold the view and be open to it changing.

3. Submission titles must adequately sum up your view and include "CMV:" at the beginning.

4. Only post if you are willing to have a conversation with those who reply to you, and are available to start doing so within $3 \mathrm{~h}$ of posting.

\section{Comment Rules:}

1. Direct responses to a CMV post must challenge at least one aspect of OP's stated view (however minor), or ask a clarifying question.

2. Don't be rude or hostile to other users.

3. Refrain from accusing OP or anyone else of being unwilling to change their view.

4. If you have acknowledged/hinted that your view has changed in some way, please award a delta.

5. No low effort comments.

It is worth noting, relative to Sect. 2 above, that these are procedural rules that aim to foster a particular communicative activity where the point is for participants to define an issue about a topic and then attempt to persuade each other about what position to take on that issue by making arguments and otherwise. ${ }^{6}$ Importantly, the value of CMV's procedural rules for the present study is that it fosters the uses of arguments to manage disagreement without specifying, in particular, material preconditions on the activity or the informal, implicit, and the substantive aspects of how collectives argue. These must emerge through the discussion and thus an appropriate challenge for argument mining of argument patterns.

\footnotetext{
${ }^{6}$ It is remarkable how closely CMV's procedural rules, such as those for submitting and commenting, reflect the normative rules for the critical discussion ideal theorized by Pragmadialectians (Van Eemeren and Henkemans 2016: 182-183). For instance, the rules defining a normatively ideal critical discussion include: Rules 1, 6 and 7 constitute an application of the freedom rule ("Parties must not prevent each other from advancing standpoints or from casting doubt on standpoints"); Rule 4 guarantees that the burden of proof rule ("A party that advances a standpoint is obliged to defend it if asked by the other party to do so") is respected; Rule 5 is a rule about making making a standpoint ("A party's attack on a standpoint must relate to the standpoint that has indeed been advanced by the other party"); and finally, Rule 8 is about achieving resolution and closure ("A failed defense of a standpoint must result in the party that put forward the standpoint retracting it"). It is as though CMV formulated primary institutional conditions for a communicative activity of what Walton (1998, pp. 89-90) calls a "persuasion dialogue" where the aim is to resolve a difference of opinion.
} 


\subsection{A Repository of Defeasible Reasoning and Persuasive Strategies}

CMV is a repository of actual examples of non-monotonic, defeasible reasoning (Pollock 1987) since in being willing to change their view users admit that their claims are presumptions potentially subject to retreat, once other information is added. Furthermore, users award a so-called Delta point to users that managed to change their views and explain why, thus, participants (and analysts) can see information about which arguments turn out to be more defeasible and which are perceived as more persuasive and why.

A schematic rendering of a CMV discussion thread, as represented in Fig. 3, illustrates the branches of the discussion that flow from the same original post. Not all comments achieve persuasion as, in this case, only A.1 received a delta point.

For the purposes at hand, the contrasts between posts that have achieved a Delta point, and those that have not, offer clues about the most relevant critical questions and patterns of moves that most effectively brought the argumentative materials to bear on the question. CMV data make it possible to ascertain how communities of arguers establish what counts as persuasive and what kind of arguments matter. This opens the possibility of interrogating, for instance, whether the set of critical questions that have been associated to argumentation schemes in the Informal Logic Tradition may not, in fact, be plausibly perceived as equally relevant across different fields, spheres and institutions (e.g., in case law accepted lines of reasoning might not be considered as such in everyday discussion).

\subsection{A Natural Set for Polylogues}

$\mathrm{CMV}$, as the majority of other online fora, is by nature a polylogical setting where multiple positions are pursued among multiple players across multiple venues. Studying the polylogical character of argumentation has serious implications for modeling argumentation (Lewiński 2014; Lewiński and Aakhus 2014). For instance, even the seemingly straightforward coding of text as 'agree' and 'disagree,' which is pervasive in argumentation research and, in particular in computational analysis, is complicated by the polylogical nature of argumentation. Consider a relatively simple situation that involves three parties and three positions following Lewiński and Aakhus (2014) illustration: if A and B disagree with C they do not necessarily agree with each other. Moreover, the truth of position $\mathrm{Q}$ may entail the falsity of positions $\mathrm{E}$ and $\mathrm{D}$ but the falsity of $\mathrm{Q}$ does not entail the truth of either $\mathrm{E}$ or D. Positions and players can become intermingled in complex ways even in what may seem to be rather simple situations. CMV threads typically involve more than two participants each pursuing lines of doubt or disagreement with the OP or with subsequent contributions.

CMV discussions have polylogical qualities and thus present an opportunity to reconstruct the disagreement space(s) and argumentative footprint of a collective without forcing a di-logical reduction of argumentation (see Lewiński and Aakhus 2014). Moreover, there are often several CMV threads addressing the same general topic, such as the fracking threads analyzed below, and thus various places for managing differences and pursuing disagreement regarding the broad issue at stake. 


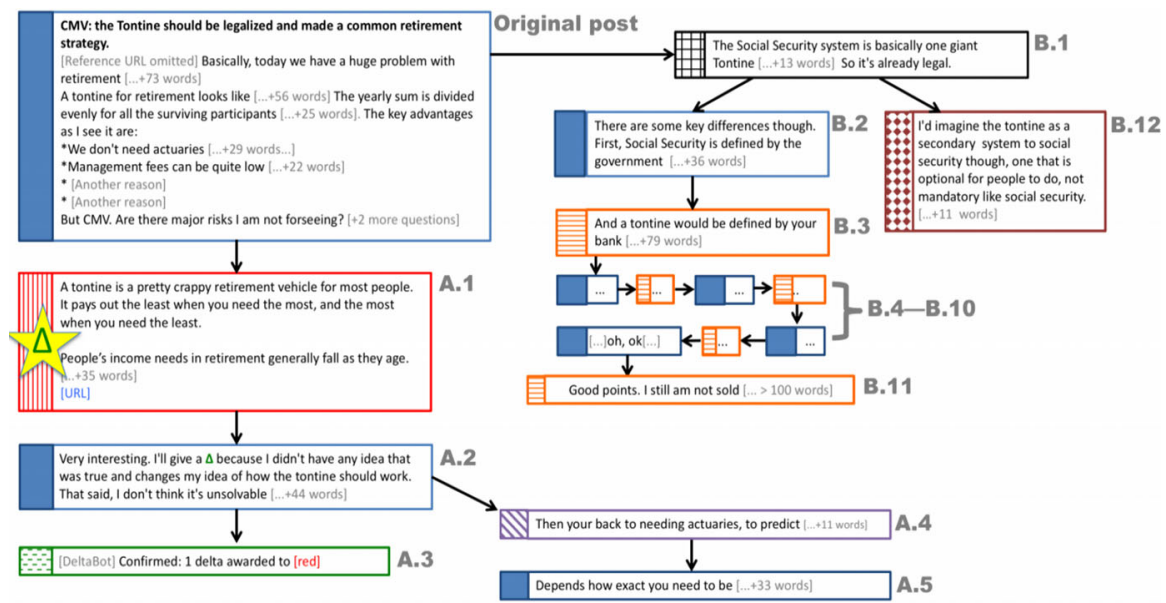

Fig. 3 Example of winning and non winning comment threads (Tan et al. 2016)

To model polylogues, it is essential that the descriptive modeling of argumentation trace what is made an issue and the lines of argumentation for the various positions taken up on the various issues. CMV affords the ability to examine the variations in the way different groups of people negotiate the issues, emphasize particular critical questions, and develop argumentative materials to persuade each other. CMV is thus an excellent environment to develop and refine a methodology for the retrieval of argumentative patterns pertinent to the polylogue of a collective based on discursive, linguistic features able to scale across domains and genres.

\subsection{Data: A CMV Corpus for Observation and Analysis}

To build a corpus for analysis, discussions threads were retrieved containing the keywords "oil drilling"; "fracking" and "hydraulic fracturing." Six threads were selected 6 and the structural features of each is summarized in Table 1. The sample of threads were selected to maximize the variation of the sampled threaded discussions while maintaining common points of comparison and including the widest possible variety of arguments about energy issues in the drilling/fracking context. So, two threads with an OP that is pro oil drilling/fracking (Threads 2 "Pursue", 3 "BuildKXL"), two threads with a con OP about oil drilling/fracking (Threads 4 "NoUSDrill", 5 "Ban"), and two centered around energy policies to be put into action by policy makers (Thread 1 "B's Fantasy") or by the general audience (Thread 6 "NoConsume"). The number of participants varies independently of the number of comments: while in thread six the ratio of participants to comments is $1: 1$, in thread 1 it roughly amounts to 3 . It has, however to be noticed that degree of participation of different users in the unfolding discussions is highly variable: in thread one 1, for instance, user 1 is the most active in the ongoing discussion being the author of 32/59 comments. It is the case that, at a minimum, there are more than two participants making at least one contribution to the thread. 
Table 1 Sample of analysis selected from Changemyview

\begin{tabular}{|c|c|c|c|c|c|c|}
\hline No. & Thread title & Comments & Tokens & $\begin{array}{l}\text { Tokens } \\
\text { per } \\
\text { comment }\end{array}$ & Participants & $\begin{array}{l}\text { Delta } \\
\text { points }\end{array}$ \\
\hline 1 & $\begin{array}{l}\text { Bernie Sanders' energy policy is based } \\
\text { in fantasy (B's Fantasy) }\end{array}$ & 59 & 4640 & 78.64 & 20 & 0 \\
\hline 2 & $\begin{array}{l}\text { I believe that fracking is a good option } \\
\text { for energy production and should be } \\
\text { pursued. I consider myself an } \\
\text { environmentalist (Pursue) }\end{array}$ & 21 & 2478 & 118.00 & 7 & 0 \\
\hline 3 & $\begin{array}{l}\text { I think the Keystone XL Pipeline should } \\
\text { be built for environmental reasons, } \\
\text { and protesters are fighting against } \\
\text { their own interests (BuildKXL) }\end{array}$ & 15 & 2230 & 148.67 & 11 & 0 \\
\hline 4 & $\begin{array}{l}\text { The United States should not drill any } \\
\text { oil (NoUSDrill) }\end{array}$ & 49 & 8600 & 175.51 & 15 & 0 \\
\hline 5 & $\begin{array}{l}\text { I think that fracking is a practice that } \\
\text { should be globally banned (Ban) }\end{array}$ & 6 & 956 & 159.33 & 3 & 0 \\
\hline 6 & $\begin{array}{l}\text { If you benefit from resource extraction } \\
\text { based economy then you cannot } \\
\text { condemn fracking. If you want to } \\
\text { protest fracking the true way to protest } \\
\text { is to not consume... (NoConsume) }\end{array}$ & 5 & 626 & 125.20 & 5 & 0 \\
\hline
\end{tabular}

None of the comments in the threads has been awarded a "Delta Point," which represents a symptom of a high degree of controversy and that is crucial for the purposes at hand. Understanding the reasons underlying this trend would require a comparison with discussion threads about highly debated issues in other domains (i.e., health domain), which we leave for future work.

The title of each thread is indicative of the way the contributor's OP sets up what is at issue for the discussion. Some OP's put the issue forward as a matter of value through axiological predicates (Threads 1 and 2) or as a matter of policy through speech acts of the directive type (Threads 3 and 6) or even as more or less direct recommendations. What unites the verdictive speech acts, expressed by axiological predicates, and the directive ones, expressed by the deontic modal verb should, is their belonging to the frame of human action, expressing reasons as a guide for actions. According to the Aristotelian distinction between knowledge-oriented and praxis-oriented argumentation, the issues put forward by the original posters belong to the first type. In other words, they constitute instances of what in contemporary Argumentation Theory is called "practical reasoning" (Walton 1990) but it is directed toward the institutional level moreso than the personal as the participants of the discussions cannot themselves realize the advocated actions, which are bound to public consent as well as policy makers' choices. 


\section{Application of the Macroscope to Generate Topographies}

As discussed above, prototypical argumentative patterns are understood here to uncover the network of most frequent standpoints and of arguments supporting them based on the inferential relations that are discussed by the participants to the discussion threads. However, they do not highlight what argumentative patterns become privileged targets in the polylogical discussion. Stereotypical argument patterns, on the other hand, uncover the argument schemes and argumentative reasoning aligned with the most controversial issues in a polylogue, identify what issues are brought to the fore and argued by the single participants in the discussion, and identify what issues become targets of collective argumentation throughout the polylogue. Stereotypical argument patterns are instrumental in detecting the argumentative practices of an interacting collective. In this section, the results obtained from Tier 1 annotation (i.e., prototypical patterns) are reported. The results obtained from integrating Tier 1 annotations with Tier 2 (i.e., call-out/target pairs) to identify stereotypical patterns are then reported. A specific example is then analyzed to illustrate the efficacy of the argument mining macroscope for argument patterns.

\subsection{Prototypical Argumentative Patterns}

\subsubsection{Distribution of Argument Schemes and Heteroglossic Strategies}

The Tier 1 coding of the CMV discussion threads enables the calculation of frequencies of claims and premises, argument schemes, and heteroglossic strategies and their distribution across discussion threads. The distribution of claims and premises in each thread is visualized in Fig. 4.

Not every claim is backed up by one or more premise(s) but for those claims that are supported by premises, the distribution of 160 attested argument schemes is visualized in Fig. 4 relative to each discussion thread. The attested schemes are a

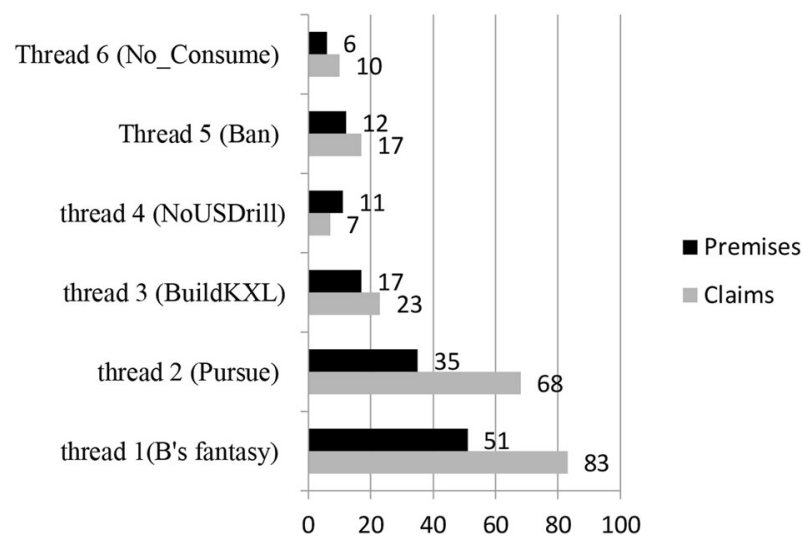

Fig. 4 Distribution of claims and premises per thread 
subset of those considered in the $A M T$ taxonomy (Fig. 1). The most frequent across all threads are the causal argument schemes $($ TOT $=58)$ and the argument scheme from 'termination and setting up' (TOT $=42$ ), which is a recommendation/ an advice about stopping/continuing/setting up state of affairs expressed in the premise is drawn from a value judgment of the same state of affairs (Morasso 2011). The mereological scheme appeared 33 times, definitional 24 times, and the analogical 2 times.

The distribution of argumentation schemes is not homogeneous across the polylogue. The qualitative analysis of the annotation has revealed that the argument schemes used by the original poster to back up his claim tend to correspond to the types of inferential relations distributed in the overall thread-that is, the relative frequency of each argument scheme is higher in those threads where the same argument scheme is used in the opening post. Whether this behavioral feature applies to argumentation outside of the CMV format or across other CMV topics calls for further analysis.

The analysis of heteroglossic strategies involves examining the use of epistentials in performing argument schemes in the negotiation of interaction. When the analysis of epistentials is combined with argument schemes, it is possible to observe how the performance of argument schemes varies across topics of discussion regarding fracking and across schemes (see Table 2). The attested epistentials entail a high degree of speaker's commitment expressing necessity (e.g., "must", "necessarily"), impossibility (e.g., "impossible”), epistemic certitude (e.g., "obvious") or direct evidentiality (e.g., "show").

Table 2 Cross-distribution of argument schemes, topics and epistentials

\begin{tabular}{|c|c|c|c|c|c|}
\hline \multirow{2}{*}{$\begin{array}{l}\text { Argument } \\
\text { schemes }\end{array}$} & \multicolumn{4}{|l|}{ Topics } & \multirow[t]{2}{*}{ Epistentials } \\
\hline & $\begin{array}{l}\text { Environmental } \\
\text { impact (threads } \\
2,3 \text { ) }\end{array}$ & $\begin{array}{l}\text { Alternative } \\
\text { forms of } \\
\text { energy } \\
\text { (threads } 6,1 \text { ) }\end{array}$ & $\begin{array}{l}\text { Energy } \\
\text { demand } \\
\text { (threads 1, } \\
5 \text { ) }\end{array}$ & $\begin{array}{l}\text { Economic } \\
\text { outcomes } \\
\text { (threads 1, } \\
4 \text { ) }\end{array}$ & \\
\hline Causal & 0 & $\mathrm{X}$ & 0 & $\mathrm{X}$ & $\begin{array}{l}\text { Obvious (1), clear (2), } \\
\text { cannot (3), impossible } \\
\text { (5), should (1), need } \\
\text { (21) }\end{array}$ \\
\hline $\begin{array}{l}\text { Termination } \\
\text { and setting } \\
\text { up }\end{array}$ & $X$ & $X$ & 0 & 0 & Should (13); need (12) \\
\hline Definitional & $\mathrm{X}$ & 0 & 0 & $\mathrm{X}$ & $\begin{array}{l}\text { Necessarily (1), show } \\
\text { (1), must (3), should } \\
\text { (2), need (1) }\end{array}$ \\
\hline Mereological & 0 & $X$ & $\mathrm{X}$ & 0 & 0 \\
\hline Analogy & 0 & 0 & & $\mathrm{X}$ & 0 \\
\hline
\end{tabular}

0, absent; X, present 


\subsubsection{Results: Topography of Prototypical Argumentative Patterns}

The correlation of the inferential and lexical levels of analysis has allowed to identify clusters of argumentative features - prototypical argumentative patternswhich are recurrent and interdependent among the posts making up the threads. The types of reasoning through which these issues are touched upon and discussed as well as the heteroglossic positioning of the speaker in the negotiation of the disagreement space through the use of epistentials have highlighted the presence of recurrent argumentative patterns.

The most frequent argumentative pattern is centered around causal argument schemes from the effect to the cause or from means to goals. Reasoning about future actions or future consequences of actions is at the core of the attested causal argument schemes, where standpoints are for the $80 \%$ of cases interpretative propositions of the predictive type presented as inter-subjective through the use of concurrence markers. This type of standpoint is mainly attested when the economic effects of policies regarding oil drilling/fracking are discussed. Foreseeing future events represents, in fact, a central speech act in the economic domain (Walsh 2004, 2006; Donohue 2006). Alternatively, causal relations are used to ponder on feasibility of alternative energy sources.

The second argumentative pattern in terms of frequency is characterized by argument schemes from termination and setting up. ${ }^{7}$ These recommendations about setting up or avoiding future actions are expressed through deontic modals or necessity epistentials as the result of subjective or inter-subjective pragmatic reasoning through markers of Pronouncement or Concurrence.

Beyond causal and practical reasonings typical of pragmatic argumentation, reasoning from definition is present. These evaluative propositions are drawn from the observation of properties of events presented as intersubjectively accessible through concurrence markers. As clarified by the lexical semantics of these predicates (i.e., counterproductive, safe) or by the context of utterance (i.e., good for the economy) the positive or negative value of oil drilling and/or fracking are decided on the basis of sustainability in terms of energy demand as well as environmental impact, taking into account other possible alternative energy sources.

Peripheral argumentative patterns are based on argument schemes of the mereological and of the analogical type. Both types of reasoning connect premises and claims that do not contain explicit markers of rhetorical relations. As to mereological argument schemes, this behavior is due to the type of inductive reasoning at stake: it draws generalizations regarding the economic costs of oil drilling as well as the environmental consequences from either the authors' personal experience or from events that happened in the past.

\footnotetext{
7 Argument schemes from "termination and setting up" are distinct from causal argument schemes in that they always feature as a premise an evaluative proposition instead of a descriptive factual proposition. Differently from causal ones, they belong to the class of extrinsic argument scheme. However, it has to be remarked that argument schemes "from termination and setting up" are pragmatically similar to causal argument schemes of the final type as instances of practical reasoning.
} 
As an example of the interaction between argumentative schemes and heteroglossic strategies the following two instances of arguments from definition can be considered:

(3) ["The panels require rare earth metals. These must be mined and there is a

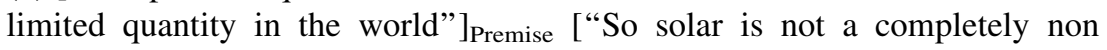
consumptive energy source" $]_{\text {Claim }}$

(4) ["It is absolutely impossible for fracking water to pollute the environment during the fracking process"] $]_{\text {Claim. }}$. [The water shelf is only a couple hundred feet under the ground. Fracking occurs at over 10,000 $\mathrm{ft}$ underground by cracking open shale and retrieving the natural gas out of the pores in the shale. There are many, many layers of rock between this and the water shelf. It is impossible for anything at that depth to miraculously travel upward through these layers about 2 miles and leech into the water supply [...] $]_{\text {Premises. ["The }}$ point of this long winded post is that fracking in and of itself is a very useful tool that is perfectly safe" $]_{\text {MajorClaim }}$

As shown in (3) and (4), the premise/claim in support of the claim/major claim list definitional properties which allow the attribution to solar energy the predicate "not a non consumptive energy sources," and to fracking the predicate "perfectly safe." Table 2 shows that the argumentative components linked by definitional inferential relations mainly contain deontic modals (cf. 3) or epistentials (cf. 4) that entail a high degree of commitment. They are generally positioned in the premises, where they express concurrence: in example (3) the deontic modal verb must frames the mining process as a sine qua non requirement for the construction of solar panels, presenting it as part of the common ground. In example (4), the predicative construction it is impossible, modified by the intensifier absolutely, work as an epistential, assuming an evidential inferential function next to an epistemic modal one: the impossibility for fracking water to pollute the environment during the fracking process is drawn as an inference from a set of factual subsequent premises. The evidential value shifts the authorial emphasis lexically conveyed by the modal value-endorsements-towards an intersubjective positioning: the hearer, having access to the premises, can go through the same inferential path undergone by the speaker, concurring with his or her impossibility judgment. From a rhetorical perspective, the use of markers of concurrence in propositions functioning as premises has the function of presenting the evaluations as intersubjective and, thus, more easily acceptable.

\subsection{Stereotypical Argumentative Patterns}

The prototypical argumentative patterns unraveled above provide a picture of the plausible network of issues raised by every single user but do not reveal the actual network of issues that emerge within the disagreement spaces and across the polylogue represented by the six threads about fracking analyzed here. In Sect. 2, it was discussed that for the macroscope proposed here that prototypical patterns are taken to mirror the set of arguments raised as logical products by single users, while stereotypical patterns identify the arguments used in the arguing process. The 
stereotypical patterns represent those argument patterns that emerge as a social product from the discussion process and reveal the disagreement space. By building these representations, the macroscope proposed here aids the identification of stereotypical argumentative patterns that revolve around the controversial issues constituting disagreement space of the polylogue while enabling the reconstruction of the way the ways a community manages differences and pursues disagreement through arguments.

\subsubsection{Distribution of Claims and Premises in CallOuts and Targets}

To retrieve stereotypical argument patterns, Tier 2 annotation was incorporated to examine how argumentative components are distributed across CallOuts and Targets. While both claims (see example 5, taken from Thread x) and premises (see example 6, taken from Thread x) can be targeted, CallOuts, which express the existence of a potentially divergent stance can include at least one claim and may encompass premises (see example 7, taken from Thread x), but not necessarily (see example 8, Taken from Thread $\mathrm{x}$ ):

(5) Claim as Target: \{[I'm not sure if I would say that Chernobyl and Fukushima were necessarily catastrophic events $\left.]_{\text {Claim }}\right\}_{\text {Target }}$.

(6) Premise as Target \{[Those methods accounted for about $6 \%$ of all generated electricity.] Premise $^{* *}$ Additionally, [all the methods that Sanders favors are very geographically dependent and require grid-scale energy storage for which we have no viable solutions $\left.]_{\text {Premise }}\right\}_{\text {Target }}$

(7) CallOut with Claim and Premises: \{While I also agree that we should use less energy, [we still need to use energy and that energy has to come from somewhere $]_{\text {Claim. }}$. [As far as solar, it cannot come close to meeting the energy demands of this country] Premise. [While solar is growing it is expected to be only $0.5 \%$ of the countries (http://www.eia.gov/forecasts/steo/report/renew_ co2.cfm) energy needs $\left.]_{\text {Premise }}\right\}_{\text {CallOut }}$

(8) CallOut with no Premises $\{[$ Contamination of ground water isn't the most concerning negative aspect of fracking $\left.]_{\text {Claim }}\right\}_{\text {CallOut }}$

Following on these examples and the discussion of Targets and CallOuts in Sect. 3, the Tier 2 annotations enable the representation of aspects of the arguing process essential to analyzing disagreement space across polylogues. To do so, the macroscope represents that the same claim can, in fact, be called-out by different participants in the discussion and/or it can be introduced as a CallOut that is then targeted in the discussion flow. For example 2 above, the claim "I would say anything that needs to be shipped by tanker over the ocean would qualify as foreign" is first used to CallOut a previous claim ("That being said, for anyone who says the Keystone Pipeline will limit dependence on foreign oil, your definition of ।"foreign।" is non-white"), while it then becomes the target of a subsequent CallOut pointing rebutting its truth ("What? Everything that crosses a national border is foreign."). The frequency of claims/premises that function as both target and callout are indicative of the polylogical nature of the disagreement space. 
For the purposes at hand the annotation has retrieved every claim and premise which appears in Targets and/or CallOuts. It has to be noted that the presence/ absence of premises next to claims as part of a Call-Out provides information about the relevance that supporting arguments have for the annotator in identifying a point of view about different issues. To study the management of stance and how it is perceived, however, would require a comparison of different annotators' behavior which goes beyond the scope of proposing the macroscope here but should be taken into account in future work.

The combination of coarse and the finer grained annotation of argumentative components shows the distribution of argument components from the Tier 1 annotation across the coarse-grained components from Tier 2 relative to each discussion thread (see Fig. 5). The distributions visualizes the character of the disagreement space for the fracking polylogue in CMV. For instance, Thread 4 (NoUSDrill) has a higher proportion of argument components in CallOuts and Targets (65 of 87 premises and 81 of 88 claims) compared to the one of six premises and three of 35 claims in Thread 6 (NoConsume). The disagreement space is more developed in Thread 4 than Thread 6 or the others. Because the macroscope can reveal these ratios, future work could construct an index indicative of the degree to which a disagreement space is present and developed and thus a way to better understand what issues are developed and where these are developed.

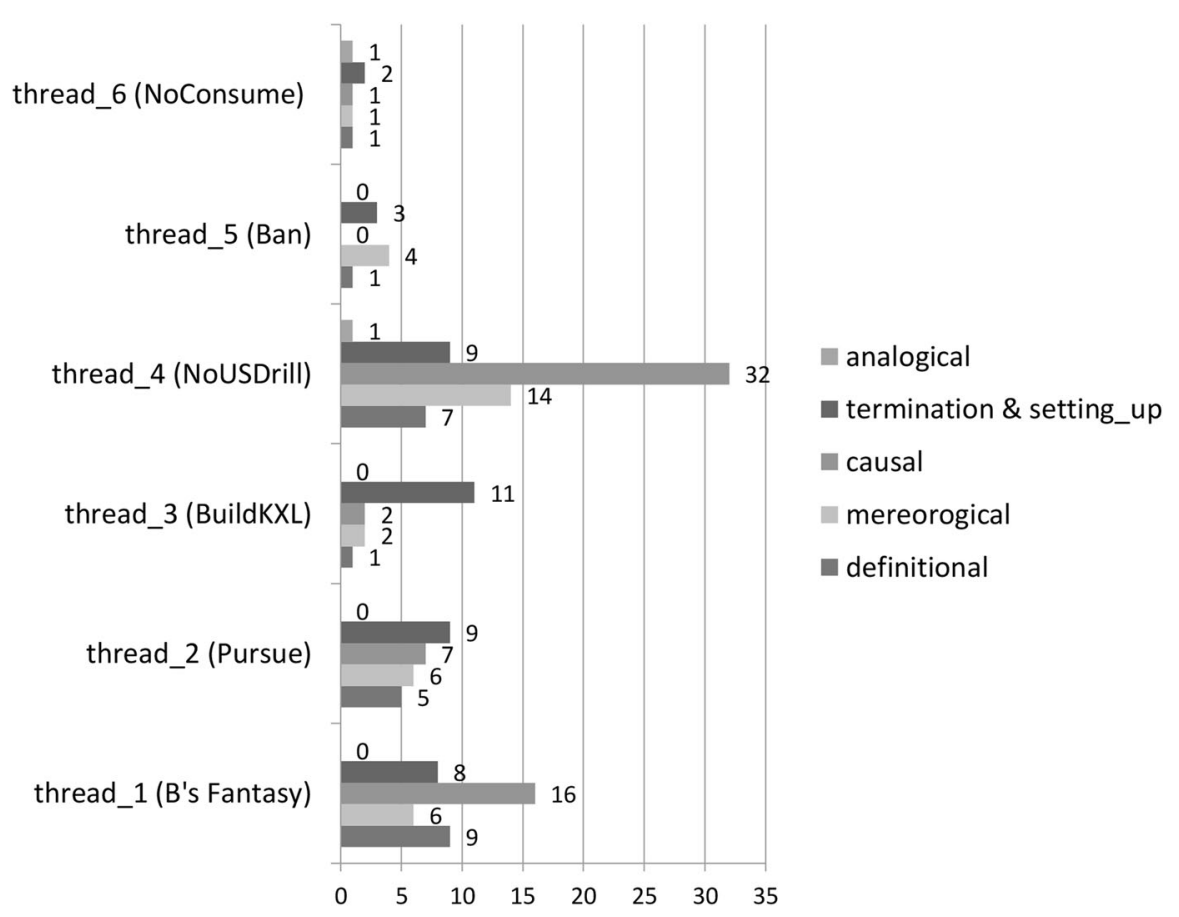

Fig. 5 Distribution of argumentation schemes per thread 
Furthermore, the distribution of components relative to disagreement and thread, enables a closer examination of how argument components are put into play in the arguing process. For example, examination of the distribution of claims can show what kinds of claims are taken up or not in the development of arguments in disagreement. From Fig. 6, it is clear that across the different threads claims can frequently lie outside Targets and CallOuts. To understand what claims were more likely to be called out or not, text from threads with a high ratio of claims not in CallOuts were qualitatively analyzed. In thread 5 (Ban) 12 of 13 claims were not in either a Target or CallOut and one of 13 was in a CallOut while in thread 3 (BuildKXL) 122 of 134 claims were not in either a Target or CallOut and 11 were in a CallOut. The claims which are always included in a CallOut are those inherently dialogical since overtly expressing agreement/disagreement (i.e., "You are stuck with a false dichotomy", thread 3; "I agree that humans are changing the atmosphere through our actions and that has negative consequences", thread 2) or mitigated disagreement in the case of concessive constructions (i.e., "Sure, some

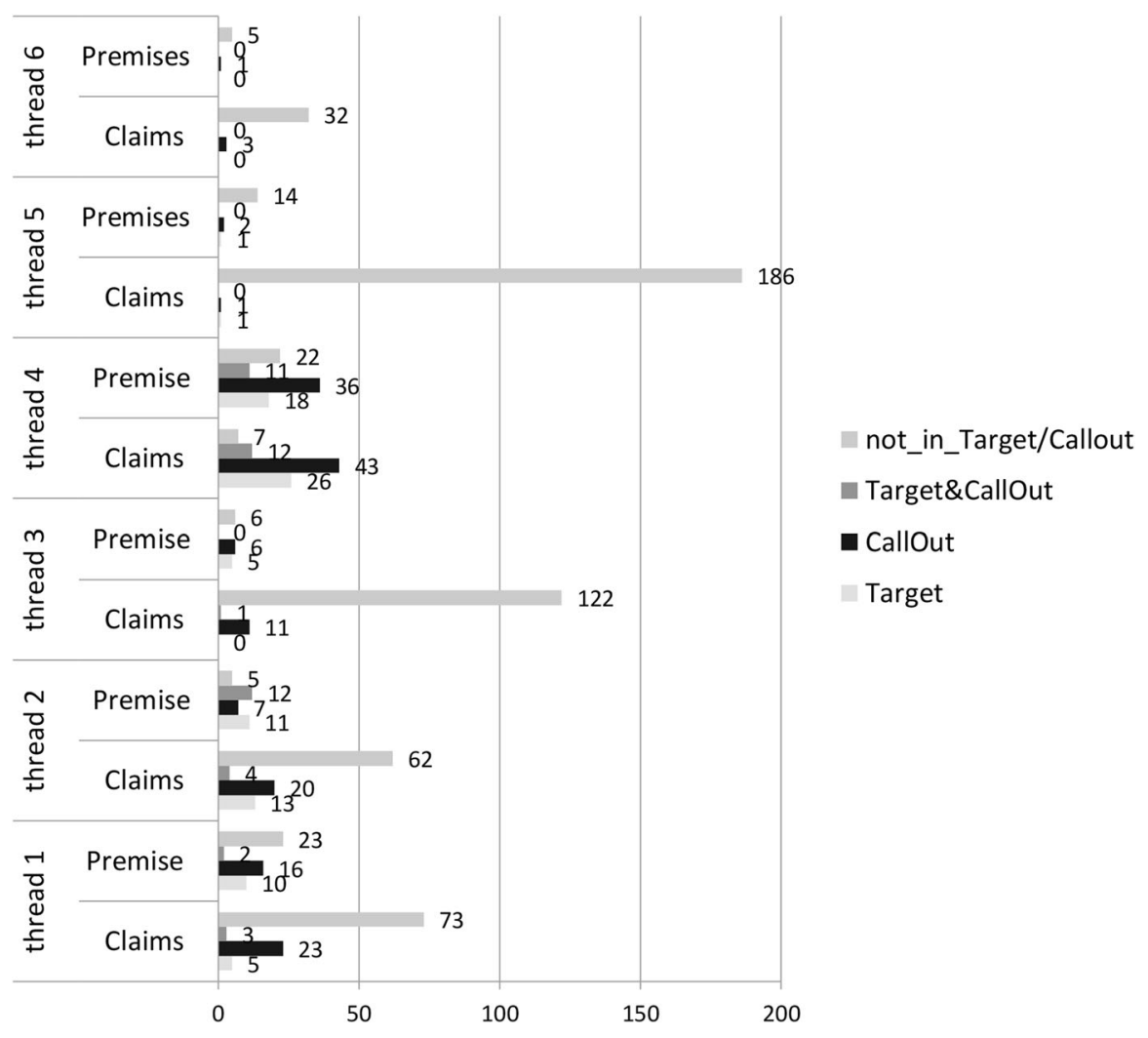

Fig. 6 Distribution of claims and premises in CallOuts and Targets (from the comparison with Fig. 5 it emerges that only a minor portion of premises and claims constitutes targets or calls-out pointing to the importance of distinguishing arguments recurrently advances from those that are particularly controversial) 
forms of power can fluctuate a little or require particular geographies-but that doesn't mean they are not viable.", thread 1), thus entailing the existence of a different point of view. On the other hand, claims that do not directly assert a stance, such as those of the interrogative form (i.e., "What's worse: a process that produces a thimbleful each of contaminated wastewater, $\mathrm{Co} 2$, methane, and exhaust gases, or one that produces twenty million gallons of contaminated wastewater?", thread 5) or those that do not clearly anaphorically point to a previous stance can function as Targets, but are not recognized as CallOuts. This qualitative analysis based on the distribution of argument components is suggestive of a variety of closer analyse that could be performed for revealing the argumentative footprint of a polylogue.

\subsubsection{Results: Topography of Stereotypical Argumentative Patterns}

To identify the use of reasoning patterns in the management of differences and pursuit of disagreement in the polylogue, the argument schemes present in Target and in CallOuts were retrieved. Their distribution is presented in Fig. 7.

There are 20 Termination and Setting Up, 47 Causal, and four definitional argument schemes appearing in Targets or CallOuts across the threads. Comparing the distributions of schemes within all comments (Fig. 5) and schemes in Targets, CallOuts, or both (Fig. 7) the uses argument schemes in Targets and CallOuts do not use Merological or Analogical argumentation schemes, which differs from the usage in overall comments. The order of frequencies of the other argument schemes is, instead, maintained, with Causal appearing 47 times in Targets or CallOuts and 59 times overall, Termination and Setting Up appearing 20 times and 42 times respectively, and Definitional appearing four and 24 times respectively. However, the rate of appearance holds most strongly for the Causal scheme while rate of

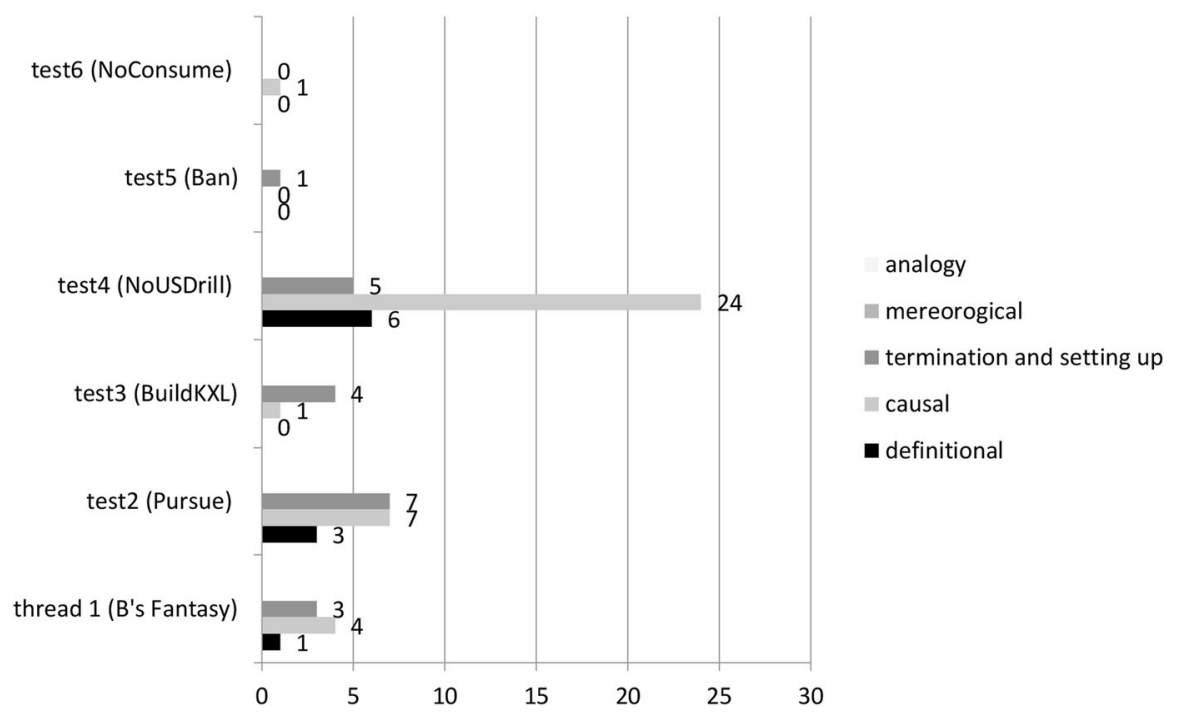

Fig. 7 Distribution of argumentation schemes in CallOuts and Targets 
appearance for Termination and Setting Up was about one-half and for Definitional about one-sixth of the appearance across all comments.

The absence of Mereological and Analogic argument schemes in Targets and CallOuts is noteworthy. As explained in Sect. 5.1.1 claims and premises linked by mereological and analogical argument schemes in this corpus are not marked by epistential rhetorical strategies. These strategies make explicit engagement that, due to their pragmatic function, invites other speakers to take part in the negotiation of stances and reasoning (Martin and White 2003: 97). The Causal, Termination and Setting Up, and Definitional schemes in this corpus tended to be associated with the use of epistentials. The Mereological and Analogical argument schemes were never attested in the original post where the issue is set up and opened for negotiation in this corpora. Moreover, zooming into the occurrences of these two argument schemes it seems that they tend to appear in a peripheral position in the comments and are not used to support a claim directly supporting or attacking the stance of a previous user. These two schemes were used to specify where the truth of some premises has been drawn from.

On the other hand, the most relevant stereotypical patterns are argument moves where: (1) the effects of present states of affairs are claimed through causal reasoning and marked as inherently intersubjective through concurrence rhetorical markers; and, (2) recommendations about stopping/carrying out a oil drilling fracking actions are drawn from positive and negative evaluations presented as highly shareable.

Across the threads of discussion for fracking clear patterns for the lines of reasoning used in managing differences and pursuing disagreement had strong patterns. Where the disagreement space was most developed as evident by the proportion of claims and premises in Targets and CallOuts (see Fig. 6), the use of Causal and Termination and Setting Up schemes were prominent. In Thread 4 (NoUSDrill), which had the most claims and premises in Targets and CallOuts, the causal scheme was most prominent and in Thread 2 (Pursue), where the second most claims and premises were in Targets and CallOuts, the Termination and SettingUp and Causal schemes were equally prominent. Each thread has a pattern and the threads taken together suggest that in the broader polylogue about fracking there was a common way of managing differences and pursuing disagreement. The proposed macroscope thus appears to detect pattern and variation of argumentative behavior that can establish stereotypical argument patterns across and within communities.

\subsection{Macroscope into Practice}

As a further proof of concept for the methodology of the macroscope an extract from thread 1 (discussing Bernie Sander's policy) is considered. The crossobservation of those claims-premises pairs that are parts of CallOuts and Targets allows the monitoring of not only what issues arise in the argumentation process, but which are perceived as most controversial: 
Thread 1: "CMV: Bernie Sanders' energy policy is based in fantasy"

[...]

\section{USER 1}

"Do you know what timescales are normally needed to change power production? I'm not sure 20 years is unreasonably short"

USER 2

Call-Out/Target: Attaining 50\% renewables in 20 years is impossible. I'm not even being hyperbolic. I work closely with a lot of scientists that are working on batteries and it would take a miracle for someone to develop the technology and manufacturing methods for cost-competitive batteries in that time. In the meantime, we would need to start laying the groundwork TODAY for the next generation grid. So that would require convincing Congress to invest trillions into a renewable energy project that depends on a scientific miracle. And even if this miracle happens, the energy bills for nearly every American will skyrocket to the point where low-income families are spending nearly half of their after-tax income on electricity. It won't happen in 20 years.

USER 3

CallOut: I work in renewable energy law and policy here in Europe. It is definitely not physically impossible for you to at least achieve close to what Sanders hopes for in 20 years (if he started in November after taking office). He would maybe have to concede (at least in the short to medium term) on natural gas and nuclear (like you said).

RE technologies are getting cheaper and better all the time, at an amazing rate. The cost would obviously be substantial but not as bad as many skeptics claim it would.

The US has the money, labour, intellect, technology and resources to implement Sanders' plan. The only reason it is fantasy is because of the political climate in your country.

[...] It is political fantasy, but everything that is needed to physically achieve his goal is available.

User 2 calls out user User 1 answering his question and rebutting his interpretative statement, explicitly qualified as uncertain ("I am not sure"). The presence of the question justifies the annotator choice of considering not only the claim stating disagreement as part of the CallOut ("Attaining 50\% renewables in 20 years is impossible"), but also the following arguments in support. User 2 supports his claim through a concatenation of causal reasoning construed in an ascendent climax: as a first argument he states that the required means to attain renewables in 20 years cannot be produced in such a restricted time frame. He backs up the use of the hyperbolic term "miracle" used to assert impossibility appealing to his ethos ("I work in renewable energy law and policy here in Europe"). He continues stating that another forward-looking collateral action is needed to achieve the advocated aim. In turn, the realization of this action would necessarily require to convince the Congress to allocate investments: restating that the goal to be sponsored by the Congress as a "miracle' ("that depends on a scientific miracle"), the speaker immediately frames the decision of the Congress as necessarily negative. To stress 
this correlation among impossible events he calls again 'a miracle' the eventuality that the Congress provides the fundings. Reasoning per absurdum he imagines, through the concessive construction "even if this miracle happens", a possible world in which it could be the case: even in that scenario the cost of the energy bills would be an unbearable effect of this causal chain. To conclude his complex argumentative move he circularly reasserts his initial claim.

User 3 attacks User 2 through what initially looks like a traditional rebuttal ("It is definitely not physically impossible to achieve [...]"), marked for pronouncement through the epistential adverb impossible, further reinforced by the adverb definitely.

However, the following unfolding of arguments reveals the relevance of the adverb "physically" in grasping the disagreement space. The speaker, who ad incipit collocates himself at least at the same level of expertise with respect to the previous user ("I work in renewable energy"), counters the lack of technologic and economic means and shifts the burden of proof towards political reasons. In touching upon the costs required to build renewable energy, he concedes that they would be high marking the state of affairs as shared knowledge through the adverb obviously, but continues debunking their unaffordability.

This exchange of comments brings about a critical question which challenges the scope of the original poster's claim: the features that allow to define Sander's energy policy as "based in fantasy" do not pertain to factual resources, but to political reasons.

\section{Conclusions}

The basic design of a macroscope for the discovery of the unique argumentative footprint that characterizes how particular collectives manage differences and pursue disagreement in polylogues was proposed and tested here. The macroscope addresses the broader analytic problem posed by argumentation theories about the argumentation of groups, organizations, and communities by contributing a theoretically motivated procedure to trace back the specimena of argumentative realities presupposed by various conceptualizations of large-scale argument such as fields, spheres, communities, and institutions. More specifically, the macroscope's design incorporated a two-tiered method for the mining of argument patterns that retrieves arguments as performed in the process of arguing. The macroscope is designed to produce topographies of argument behavior across a polylogue that reveals the argumentative footprint of an interacting collective. There are three main contributions of this study in designing and implementing a macroscope.

First, at the theoretical level, the design put forward conceptualized the detection of argument patterns as arguments within arguing processes so that the uses of arguments in disagreement space could be identified relative to other uses of reasons. While inspired by the extended pragma-dialectical model's conceptualization of argument patterns, that associated approach is focused on characterizing the uses of a specific argument pattern, such as pragmatic argument, across differing institutional contexts. The aim advances particular directions of investigation from 
that model. For the purpose of characterizing the argumentative footprint of a collective, an alternative conceptualization for retrieving argument patterns was formulated. The problem taken up here involved characterizing the argumentative footprint of a collective, which means identifying the means for managing disagreement through the use of argument. For this purpose, the key design premises for the macroscope were drawn from the approaches of Disagreement Management and ATM. Prototypical arguments patterns were defined as those that achieve highest raw frequency in discourses around a controversial topic. Stereotypical argumentative patterns are those that become typical Targets of (dis)agreement in an ongoing polylogue as participants CallOut claims, premises, inferential relations, or presentational framing of arguments. Not all arguments fit such a criteria regarding what a collective treats as more pragmatically relevant in constituting the main focus of (dis)agreement. The design premises set parameters for a macroscope that identifies what communities make controversial and how the disagreement space is managed.

Second, at the methodological level, the key design premises were translated into a formalization suitable to implementation of computational models for the automatic mining of arguments and further realized in a proposed two-tier method. Systematic annotation guidelines are developed that support the integration of several computational text analysis tools and human coding. For Tier 1 annotation of arguments, three levels of argument structure, argument schemes and heteroglossic strategies are incorporated drawing on prior work from argument mining, AMT, and appraisal theory. For Tier 2 annotation of arguing involves unitizing argumentatively related segments of text as Targets and CallOuts based on prior work about disagreement management and argument mining. By identifying which claims and premises (and their inferential relations and presentational features) are part of call-outs and/or targets in interaction among participants to a discussion it is possible to see which participants treat as relevant to what is controversial, and thus stereotypical. The two-tier method, furthermore, enables the generation of various topographies of arguments performed in arguing in an interacting collectives polylogical engagement.

Third, as a proof of concept, the devised methodology is applied to the analysis of six discussion threads about oil drilling and fracking from the subreddit Changemyview. A topography of stereotypical argumentative patterns was the main output of the macroscope. The implementation of a prototype of the macroscope demonstrated its potential for understanding the argumentative reality of collectives managing differences and pursuing disagreements in polylogues. It was possible to see how the arguments performed in arguing varied across threads-indeed, some threads were much more marked by disagreement management than others. It was also possible to see the characteristics of the stereotypical argument patterns in terms of claims/premises, inferential relations, and presentational devices. The implementation reveals the promise of the proposed macroscope for further use in uncovering how discourses are built around stereotypical argumentative patterns across a polylogue and within particular places of argumentative activity in the polylogue. 
Future work must address both key limitations in the present proposal and implementation of macroscope as well as what it promises for characterizing the argumentative reality of collectives and polylogues. Tier 1 coding remains highly dependent on expert annotation and this is unlikely to change in the near future. However, as sufficient amounts of text are annotated reliable training data will be produced for computational classification experiments. The results may scaffold the work of expert annotators. In addition, further development of the annotation guide might be tailored to breaking the Tier 1 coding into tasks distributable among a team of expert annotators to gain efficiencies and reproducibility. Larger data sets that involve multiple expert annotators for Tier 1 and novice annotators for Tier 2 with data verified as to topic and text genres will enable the calculation of inter-annotator agreement as a further proof of the guideline's reliability, provide reliable training data to be used in computational classification experiments, and to compare argumentative patterns in different argumentative contexts at a greater scale.

Open Access This article is distributed under the terms of the Creative Commons Attribution 4.0 International License (http://creativecommons.org/licenses/by/4.0/), which permits unrestricted use, distribution, and reproduction in any medium, provided you give appropriate credit to the original author(s) and the source, provide a link to the Creative Commons license, and indicate if changes were made.

\section{References}

Aakhus, Mark. 2013. Deliberation digitized: Designing disagreement space through communicationinformation services. Journal of Argumentation in Context 2(1): 101-126.

Aakhus, Mark, and Marcin Lewiński. 2017. Advancing polylogical analysis of large-scale argumentation: Disagreement management in the fracking controversy. Argumentation 31(1): 179-207.

Aakhus, Mark, and Marcin Lewiński. 2011 Argument analysis in large-scale deliberation. In Keeping in touch with pragma-dialectics, ed. Feteris, Eveline T., Bart Garssen, and A. Francisca Snoeck Henkemans, 165-183.

Aakhus, Mark, Smaranda Muresan, and Nina Wacholder. 2013. Integrating natural language processing and argumentation theories for argumentation support. OSSA 10: Virtues of Argumentation 1: 1-13.

Aakhus, Mark, Paul Ziek, and Punit Dadlani. 2016. Argumentation in large, complex practices. OSSA Conference Archive 54. http://scholar.uwindsor.ca/ossaarchive/OSSA11/papersandcommentaries/ 54.

Andone, Corina. 2016. Argumentative patterns in the political domain: The case of European parliamentary committees of inquiry. Argumentation 30(1): 45-60.

Becker, Maria, Alexis Palmer, and Anette Frank. 2016. Argumentative texts and clause types. In Proceedings of the 3rd workshop on argument mining, 21-30.

Börner, Katy. 2011. Plug-and-play macroscopes. Communications of the ACM 54(3): 60-69.

Donohue, James P. 2006. How to support a one-handed economist: The role of modalisation in economic forecasting. English for Specific Purposes 25(2): 200-216.

Fahnestock, Jeanne. 1999. Rhetorical figures in science. Oxford: Oxford University Press.

Feteris, Eveline T. 2016. Prototypical argumentative patterns in a legal context: The role of pragmatic argumentation in the justification of judicial decisions. Argumentation 30(1): 61-79.

Freeman, James B. 2000. What types of statements are there? Argumentation 14(2): 135-157.

Freeman, James B. 2011. Argument structure: Representation and theory, vol. 18. Berlin: Springer.

Garssen, Bart. 2016. Problem-solving argumentative patterns in plenary debates of the European parliament. Argumentation 30(1): 25-43.

Ghosh, Debanjan, et al. 2014. Analyzing argumentative discourse units in online interactions. In Proceedings of the first workshop on argumentation mining, 39-49.

Goffman, Erving. 1981. Forms of talk. Philadelphia: University of Pennsylvania Press. 
Goodnight, G.Thomas. 2012. The personal, technical, and public spheres of argument: A speculative inquiry into the art of public deliberation. Argumentation and Advocacy 48(4): 198-210.

Goodnight, G. Thomas. 1991. Controversy. In Argument in controversy: Proceedings of the seventh SCA/ AFA conference on argumentation. Annandale, VA: Speech Communication Association.

Goodwin, Paul D., and Joseph W. Wenzel. 1979. Proverbs and practical reasoning: A study in socio-logic. Quarterly Journal of Speech 65(3): 289-302.

Henkemans, A.Francisca Snoeck. 2016. Argumentative patterns in over-the-counter medicine advertisements. Argumentation 30(1): 81-95.

Jackson, Sally. 1992. Virtual standpoints and the pragmatics of conversational argument. Argumentation Illuminated 1: 260-269.

Jackson, Sally, and N. Lambert. 2015. A computational study of the vaccination controversy. Presented at the 1st European conference on argumentation, Lisbon, Portugal.

Jacobs, Scott. 1987. The management of disagreement in conversation. Argumentation: Across the Lines of Discipline 3: 229-239.

Jacobs, Scott, and Sally Jackson. 1981. Argument as a natural category: The routine grounds for arguing in conversation. Western Journal of Communication (includes Communication Reports) 45(2): $118-132$.

Jacobs, Scott, and Sally Jackson. 1992. Relevance and digressions in argumentative discussion: A pragmatic approach. Argumentation 6(2): 161-176.

Jacobs, Scott, and Sally Jackson. 2006. Derailments of argumentation: It takes two to tango. In Considering pragma-dialectics, ed. Peter Houtlosser, and Agnes van Rees, 121-133.

Kiefer, Ferenc. 1988. Linguistic, conceptual and encyclopedic knowledge: Some implications for lexicography. In Proceedings of the 3rd EURALEX international congress, 1-10. Akadémiai Kiadó.

Kienpointner, Manfred. 1992. Alltagslogik. Struktur und Funktion von Argumentationsmustern. Friedrich Frommann Verlag Gunther: Stuttgart.

Lewiński, Marcin. 2014. Argumentative polylogues: Beyond dialectical understanding of fallacies. Studies in Logic, Grammar and Rhetoric 36(1): 193-218.

Lewiński, Marcin, and Mark Aakhus. 2014. Argumentative polylogues in a dialectical framework: A methodological inquiry. Argumentation 28(2): 161-185.

Martin, James R., and Peter R. White. 2003. The language of evaluation, vol. 2. Basingstoke: Palgrave Macmillan.

McKerrow, Ray E. 1980. Argument communities: A quest for distinctions. In Proceedings of the Summer conference on argumentation, 214-227. Falls Church, VA: Speech Communication Association.

Miecznikowski, Johanna, and Elena Musi. 2015. Verbs of appearance and argument schemes: Italian sembrare as an argumentative indicator. In Reflections on theoretical issues in argumentation theory, ed. Frans H. van Eemeren and Bart Garssen, 259-278. Amsterdam: Springer.

Mills, Glen Earl. 1968. Reason in controversy: On general argumentation. Boston: Allyn and Bacon.

Morasso, Sara Greco. 2011. Argumentation in dispute mediation: A reasonable way to handle conflict, vol. 3. Amsterdam: John Benjamins Publishing.

Musi, Elena. 2016. Dalle apparenze alle inferenze: $i$ verbi sembrare e apparire come indicatori argomentativi. Doctoral dissertation, Università della Svizzera italiana.

Musi, Elena. 2016. Strategies of objectifications in opinion articles: The case of evidentials. In Proceedings of the 11th OSSA conference 'argumentation, objectivity and bias'.

Musi, Elena, Debanjan Ghosh, and Smaranda Muresan. 2016. Towards feasible guidelines for the annotation of argument schemes. ACL 2016: 82-93.

Nuyts, Jan. 2001. Epistemic modality, language, and conceptualization: A cognitive-pragmatic perspective, vol. 5. Amsterdam: John Benjamins Publishing.

O'Keefe, Daniel J. 1977. Two concepts of argument. Journal of American Forensic Association 13(3): 121-128.

O’Keefe, Daniel J. 1992. Two concepts of argument. Readings in Argumentation 11: 79-90.

Peldszus, Andreas, and Manfred Stede. 2013. From argument diagrams to argumentation mining in texts: A survey. International Journal of Cognitive Informatics and Natural Intelligence (IJCINI) 7 (1): $1-31$.

Peldszus, Andreas, and Manfred Stede. 2016. Rhetorical structure and argumentation structure in monologue text. In Proceedings of the 3rd workshop on argument mining, ACL 2016, 103-112.

Perelman, Chaim, and Lucie Olbrechts-Tyteca. 1969. The New Rhetoric: A treatise on argumentation (trans. John Wilkinson and Purcell Weaver). Notre Dame, IN: University of Notre Dame Press.

Pollock, John L. 1987. Defeasible reasoning. Cognitive science 11(4): 481-518. 
Rigotti, Eddo, and Sara Greco Morasso. 2010. Comparing the Argumentum Model of Topics to other contemporary approaches to argument schemes: The procedural and material components. Argumentation 24(4): 489-512.

Rigotti, Eddo, and Sara Greco Morasso. 2009. Argumentation as an object of interest and as a social and cultural resource. In Argumentation and education, 9-66. Springer: Amsterdam.

Rocci, Andrea. 2008. Modality and its conversational backgrounds in the reconstruction of argumentation. Argumentation 22(2): 165-189.

Rocci, Andrea. 2012. Modality and argumentative discourse relations: A study of the Italian necessity modal dovere. Journal of Pragmatics 44(15): 2129-2149.

Rocci, Andrea. 2017. Modality in argumentation. Amsterdam: Springer.

Rosch, Eleanor, and Carolyn B. Mervis. 1975. Family resemblances: Studies in the internal structure of categories. Cognitive Psychology 7(4): 573-605.

Rowland, Robert C. 1986. The relationship between the public and the technical spheres of argument: A case study of the Challenger Seven disaster. Communication Studies 37(3): 136-146.

Sadock, Jerrold M. 1974. Toward a linguistic theory of speech acts, vol. 1178. New York: Academic Press.

Tan, Chenhao, Vlad Niculae, Cristian Danescu-Niculescu-Mizil, and Lillian Lee. 2016 Winning arguments: Interaction dynamics and persuasion strategies in good-faith online discussions. In Proceedings of the 25th international conference on world wide web, 613-624. International World Wide Web Conferences Steering Committee.

Toulmin, Stephen. 1958. The uses of argument. Cambridge: Cambridge University Press.

Tuggy, David. 1993. Ambiguity, polysemy, and vagueness. Cognitive Linguistics (includes Cognitive Linguistic Bibliography) 4(3): 273-290.

Van Eemeren, Frans H. 2010. Strategic maneuvering in argumentative discourse: Extending the pragmadialectical theory of argumentation, vol. 2. Amsterdam: John Benjamins Publishing.

Van Eemeren, Frans H. 2016. Identifying argumentative patterns: A vital step in the development of pragma-dialectics. Argumentation 30(1): 1-23.

Van Eemeren, Frans H. (ed.). 2017. Prototypical argumentative patters. Amsterdam: John Benjamins Publishing Company.

Van Eemeren, Frans H., and Bart Garssen. 2009. Problems of argumentation: An introduction. In Pondering on problems of argumentation. Twenty essays on theoretical issues, ed. F.H. van Eemeren, and B. Garssen, xi-xxi. New York: Springer.

Van Eemeren, Frans H., and Bart Garssen (eds.). 2015. Scrutinizing argumentation in practice, vol. 9. Amsterdam: John Benjamins Publishing Company.

Van Eemeren, Frans H., and A. Francisca Sn Henkemans. 2016. Argumentation: Analysis and evaluation. Amsterdam: Routledge.

Van Eemeren, Frans H., Rob Grootendorst, Sally Jackson, and Scott Jacobs. 1993. Reconstructing argumentative discourse. Studies in rhetoric and communication. Tuscaloosa: University of Alabama Press.

Van Eemeren, Frans H., and Bart Garssen. 2013. Argumentative patterns in discourse. In Proceedings of the 10th international conference of the Ontario Society for the Study of Argumentation (OSSA) (Virtues of Argumentation), ed. Dima Mohammed and Marcin Lewiński, 1-15.

Van Eemeren, Frans H., and Bart Garssen. 2014. Argumentation by analogy in stereotypical argumentative patterns. In Systematic approaches to argument by analogy, 41-56. Amsterdam: Springer.

Van Eemeren, Frans H., and Peter Houtlosser. 2015. Strategic maneuvering: Maintaining a delicate balance. In Reasonableness and effectiveness in argumentative discourse, 349-379. Amsterdam: Springer.

Wagemans, Jean H.M. 2016. Argumentative patterns for justifying scientific explanations. Argumentation 30(1): 97-108.

Walsh, Polly. 2004. Investigating prediction in financial and business news articles. In English modality in perspective: Genre analysis and contrastive studies, ed. Roberta Facchinetti and Frank R. Palmer. D. Frankfurt am Main: Peter Lang.

Walton, Douglas N. 1990. Practical reasoning. New York: Wiley.

Walton, Douglas. 1998. The new dialectic: Conversational contexts of argument. Toronto: University of Toronto Press.

Walton, Douglas, Christopher Reed, and Fabrizio Macagno. 2008. Argumentation schemes. Cambridge: Cambridge University Press.

Wenzel, Joseph W. 1979. Jürgen Habermas and the dialectical perspective on argumentation. Journal of the American Forensic Association 16(2): 83-94. 
White, Peter R.R. 2003. Beyond modality and hedging: A dialogic view of the language of intersubjective stance. An Interdisciplinary Journal of Language, Discourse \& Communication Studies 23(2): 259-284.

White, Peter R.R. 2000. Dialogue and inter-subjectivity: Reinterpreting the semantics of modality and hedging. In Dialogue analysis VII: Working with dialogue, 67-80.

Willard, Charles A. 1981. Argument fields: A Cartesian meditation. In Dimensions of argument: Proceedings for the Second summer conference on argumentation. Annandale, VA.: Speech Communication Association.

Willard, Charles A. 1996. Liberalism and the problem of knowledge: A new rhetoric for modern democracy. Chicago: University of Chicago Press.

Zarefsky, David. 2014. Persistent questions in the theory of argument fields. In Rhetorical perspectives on argumentation, 71-85. Amsterdam: Springer. 